\title{
Removal of Nitrogen and Phosphate from Fertilizer Industry Wastewater by Magnesium Ammonium Phosphate Formation and Electrochemical Treatment
}

\author{
Dong-Jin Son ${ }^{1}$, Woo-Yeol Kim ${ }^{1}$, Bo-Rim Jung ${ }^{2}$, Ki-Ho Hong, ${ }^{3, *}$ \\ ${ }^{1}$ Materials \& Membranes Co., Ltd., Gangnung-si, Gangwon-do, Republic of Korea \\ ${ }^{2}$ Green Technology Co., Ltd., Songpa-gu, Seoul, Republic of Korea \\ ${ }^{3}$ Department of Technology Fusion Engineering, Konkuk University, Seoul, Republic of Korea \\ *E-mail: khhong@konkuk.ac.kr
}

doi: $10.20964 / 2019.04 .45$

Received: 3 January 2019 / Accepted: 4 February 2019 / Published: 10 March 2019

A pilot-scale MAP (magnesium ammonium phosphate) precipitation system was applied for the removal of high-strength nitrogen compounds from fertilizer industry wastewater. The system was composed of a biological pre-treatment process for nitrate removal and a physico-chemical MAP precipitation process for ammonia removal. Although influent nitrogen loading was severely fluctuated, the stable nitrogen removal could be achieved. For the recovery of magnesium and phosphate from crystallized MAP, ammonia stripping was also conducted. The MAP precipitants could be transformed to MHP (magnesium hydrogen phosphate), and the magnesium and phosphate used for MAP formation was recovered to above $90 \%$. Also, most phosphate increasing by the supplement of phosphate and magnesium for the formation of MAP precipitants could be eliminated rapidly within 3 minutes by electrocoagulation during the electrolysis procedure.

Keywords: Fertilizer industry wastewater, Nitrogen and phosphate removal, MAP, MHP, electrolysis

\section{FULL TEXT}

(C) 2019 The Authors. Published by ESG (www.electrochemsci.org). This article is an open access article distributed under the terms and conditions of the Creative Commons Attribution license (http://creativecommons.org/licenses/by/4.0/). 